\title{
REVIEW
}

\section{Gene therapy in endocrine tumors: A comprehensive overview}

\author{
Padmanaban S. Suresh ${ }^{1)}$, Thejaswini Venkatesh ${ }^{2)}$ and Rie Tsutsumi ${ }^{3)}$ \\ ${ }^{1)}$ Centre for Biomedical Research, VIT University, Vellore-632014, India \\ 2) Institute for Stem Cell Biology and Regenerative Medicine, National Centre for Biological Sciences, Bangalore-560065, India \\ ${ }^{3)}$ Department of Public Health and Nutrition, Institute of Health Bioscience, University of Tokushima, Japan
}

\begin{abstract}
Effective treatment strategies that help tackle the complex problems associated with managing endocrine cancers are in great demand. Because of the shortcomings in current treatments and the problems associated with the treatment strategies used in the cure and/or management of endocrine cancers, considerable effort must be devoted to developing new and effective therapeutic strategies. Gene therapy represents an area of both basic and clinical research that can potentially be considered a therapeutic option in treating endocrine cancers. Therefore, we consider it timely to summarize the studies related to gene-therapy interventions that are available for treating endocrine cancers and to highlight the major limitations of and the recent progress made in these therapies. After systematically reviewing the literature, we provide a comprehensive overview of distinct studies conducted to evaluate gene-therapy approaches in various endocrine cancers. Some of these successful studies have been extended toward translational investigations. The emerging view is that an integrative approach is required to combat the pitfalls associated with gene-therapy studies, especially in endocrine cancers.
\end{abstract}

Key words: Endocrine cancers, Gene, Therapy

NUMEROUS discoveries have revealed that the pathologies of human diseases are caused by the inheritance of a single functionally defective gene [1]. Gene therapy, in its broadest sense, is a technique used for correcting defective genes that are responsible for causing diseases. Rapid developments in molecular biology research have revolutionized the various approaches used in gene therapy, as indicated by over 1800 clinical trials of gene therapy clinical having been completed to date [2]. Gene therapy clearly has great potential in clinical medicine, and the concept of gene therapy has become well established in therapeutic approaches.

Endocrine tumors develop when cells found in the tissues of the endocrine system (thyroid, adrenal gland, pancreas, parathyroid, and pituitary) become cancerous. Although several treatment options are available for each of these tumors, the underlying mechanism is not understood in the case of certain tumors. Because effective treatment options are unavailable, alterna-

Submitted Jan. 6, 2014; Accepted Mar. 25, 2014 as EJ14-0007 Released online in J-STAGE as advance publication May 14, 2014

Correspondence to: Padmanaban S. Suresh, Centre for Biomedical Research, Vellore Institute of Technology, VIT University, Vellore 632 014, Tamil Nadu, India.

E-mail: surepadman@gmail.com / surepadman@rediffmail.com tive novel treatment strategies including gene therapy have been widely studied. Endocrine glands, in particular, have been favored in targeted gene therapy because of the anatomical location of the glands, the availability of transcriptional control elements to selectively direct gene expression in the glands, and the use of tissue-specific surface proteins (hormone receptors) [1]. However, because numerous challenges remain, including the safety of gene-therapy approaches, it is critical to concisely summarize the current status of the experimental gene-therapy studies conducted in animal models and the clinical trials performed for endocrine cancers and to review the drawbacks and complications associated with these studies. Here, we aim to summarize the published studies on gene-therapy approaches used in various endocrine cancers and highlight the developments required for gene therapy to become a practical treatment in endocrine cancers.

\section{Gene therapy in pituitary tumors}

Pituitary tumors, usually adenomas, are slow-growing tumors that arise from the cells in the pituitary gland; these tumors account for approximately $10 \%-$ $15 \%$ of primary intracranial neoplasms and they often 
remain undiagnosed. By performing a meta-analysis, Ezzat and coworkers determined that the estimated prevalence of small pituitary tumors was $16.7 \%$ (14.4\% in autopsy studies and $22.5 \%$ in radiologic studies) [3]. The annual incidence rate of pituitary tumors is approximately $0.8-8$ per 100,000 persons [4]. Pituitary tumors do not commonly develop during childhood, and the peak incidence of the tumor is observed in women at ages between 20 and 45 years and in men between the ages of 35 and 60 years [5]. Pituitary carcinomas are defined by the presence of craniospinal and/or systemic metastases, and the cases of these carcinomas account for $<0.5 \%$ of all incidences of symptomatic pituitary tumors [6]. Pituitary tumors are typically classified according to their size, radiographic appearance, and endocrine function. Based on their size, the tumors are classified into microadenomas $(<1 \mathrm{~cm}$ in greatest diameter) and macroadenomas ( $>1 \mathrm{~cm}$ in greatest diameter). The invasiveness of these tumors is rated based on the radiographic appearance of the sella. Microadenomas are designated as Grade 0 (no changes in the sella) and Grade 1 (minor damages to the sella), whereas macroadenomas are classified as Grade 2 (diffuse sellar enlargement), Grade 3 (focal destruction), and Grade 4 (extensive sellar destruction and erosion) [7]. Based on their patterns of hormone production and clinical presentation, the tumors are classified as functioning and non-functioning tumors. In the functioning category, pituitary glands overproduce any of the anterior pituitary hormones (PRL, GH, ACTH, LH, FSH, or $\mathrm{TSH})$ and generate the respective clinical phenotypes. No clinical phenotype is observed in the non-functioning category, although some of these tumors produce gonadotropin/TSH- $\alpha$ subunit [8]. Treatment modalities used for a subset of tumor types include surgery, radiotherapy, and other pharmacological approaches. Transsphenoidal surgery successfully treats $70 \%-90 \%$ of the cases of microadenomas, but surgery alone is not completely successful in the treatment of macroadenomas [9]. Numerous complications are associated with macroadenoma surgery, such as diabetes insipidus, CSF leakage, meningitis, pneumocephalus, visual deterioration, and hematoma [10]. Dopamine agonists (bromocriptine, quinagolide, and cabergoline) and somatostatin analogs (octreotide and lanreotide) are used in treating prolactinomas and GH-secreting adenomas, respectively $[11,12]$. Somatostatin analogs are also used for treating TSH-secreting adenomas [13]. The symptoms and signs of pituitary failure in cases of adenomas are managed by replacing the deficient hormone, whereas hormone hypersecretion is treated using surgery, pharmacological approaches, and radiotherapy [8]. The regrowth of tumors after surgery is prevented using radiotherapy, and the most critical problem associated with radiotherapy is the occurrence of hypopituitarism after treatment. Focused radiotherapy in the form of stereotactic multiarc radiotherapy or Gamma knife can effectively avoid or diminish the damage to large, adjacent areas of the pituitary gland $[6,8]$. However, most of these treatments have certain inherent problems related to the management and treatment of various types of pituitary tumors. Therefore, new and effective treatment strategies must be developed. The successful use of recombinant DNA technology to transfer foreign genes into eukaryotic cells has opened up a new avenue for the treatment of pituitary tumors. Gene therapy appears to be a reasonable treatment strategy for pituitary tumors and several studies related to this therapy have been conducted.

Because pituitary tumors are rarely metastatic, direct administration of therapeutic vectors is highly efficient [9]. The success of any gene therapy-based treatment depends upon the type of vector used to deliver the gene to the target site, the promoter used to drive the expression of the therapeutic gene, and the therapeutic gene itself. Both viral and non-viral vectors are used in gene therapy approaches as represented in Fig. 1. Because adenoviral vectors offer several advantages, these vectors have been used in the treatment of diverse tumors [5,9]. To spare normal, adjacent tissues, specifically targeting therapeutic genes to pituitary adenoma cells is crucial. To achieve cell-specific gene expression in pituitary cells, various strategies have been followed, including direct injection of vectors into the pituitary, the use of pituitary-specific promoters $(\mathrm{GH}$, proopiomelanocortin, PRL, or glycoprotein hormone $\alpha$-subunit promoters) to ensure targeted expression, and Cre-mediated recombination to activate repressive promoters in a cell-specific manner. Another possibility is retargeting viral vector tropism, so that the vectors specifically bind to hypothalamic hormone receptors that are over expressed in pituitary tumors $[14,15]$. Although recombinant temperature-sensitive Herpes simplex virus (HSV)Type 1 vector is an efficient delivery system that can be used to transfer genes into tumors and normal anterior pituitary cells, the neurovirulence of this vector limits its potential use in humans [16]. The commonly used HSV1-TK (thymidine kinase) can 


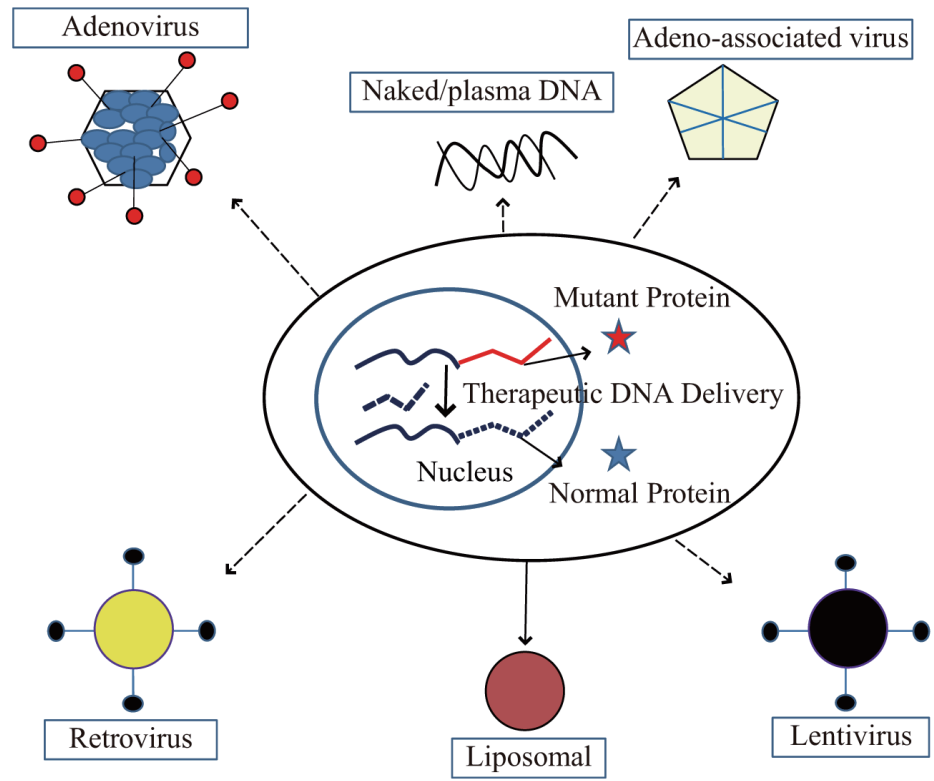

Fig. 1 Schematic diagram showing different vectors (viral/non-viral) used in gene therapy

Mutated gene replaced by corrective gene by different vectors in gene therapy approaches is represented.

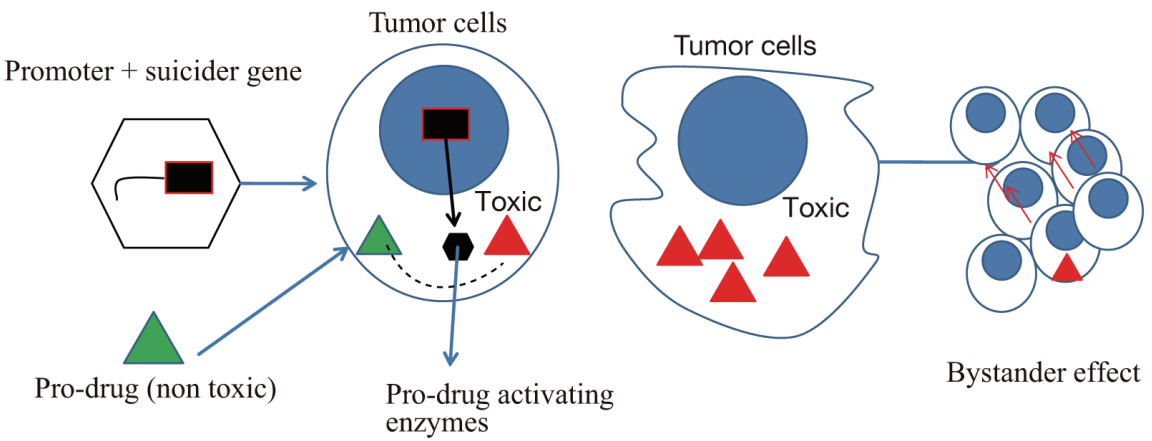

Fig. 2 Suicide gene therapy

After delivery of pro-drug activating enzymes such as herpes simplex virus thymidine kinase into the tumor cells using vectors, treatment with prodrug (ganciclovir) causes accumulation of cytotoxic metabolites in the tumor cells. The diffusion of this cytotoxic metabolites to the neighbouring cells will further kill the cells (bystander effect). Use of specific promoters helps in targeting selective endocrine tumours.

convert ganciclovir and acyclovir into phosphorylated toxic metabolites that are incorporated into the DNA of proliferating cells, which can kill the cells. Moreover, the actions of these vector systems are enhanced by the bystander effect in which phosphorylated ganciclovir can affect non-transduced neighboring cells [17]. (represented in Fig. 2). Walls et al. employed non-replicating adenoviral Serotype 5 vector to replace murine menin expression (MEN1 gene) in $\mathrm{MenI}^{+/-}$transgenic mice, which substantially reduced tumor cell proliferation [18]. Studies by Lee et al. suggested that using the proopiomelanocortin promoter could represent an effective gene-therapy strategy in the treatment of pituitary tumors causing ACTH-dependent Cushing's syndrome [19]. Both in vitro and in vivo studies have suggested suicide gene therapy employing the HSV1TKtransgene can successfully manage prolactinomas [20]. In another study on treating prolactinomas, dopamine enhancement by means of regulated, adenovirusmediated delivery of tyrosine hydroxylase suppressed the growth of estrogen-induced pituitary prolactinomas [21]. A human immunodeficiency virus Type I-derived 
vector carrying a marker gene (enhanced green fluorescent protein gene, under the control of the phosphoglycerate kinase promoter) was efficiently transduced with moderate viral loads in human pituitary adenoma cells in vitro [22]. These findings suggest that lentiviral vectors can be used to transfer therapeutic genes in pituitary adenomas. Alternatives to TK and suicide gene-therapeutic approaches include the over expression of proapoptotic factors TNF- $\alpha$ and FasL by using adenoviral vectors, which caused apoptosis in pituitary tumor cells [23]. Inhibition of angiogenesis is another effective therapeutic option available for pituitary adenomas, because neovascularization plays a key role in tumor progression. Levels of epidermal growth factor (EGF) and its receptor EGFR correlate with the aggressiveness of pituitary adenomas, and high-molecularweight forms of basic fibroblast growth factor (bFGF) have been identified in human pituitary adenomas[17]. Following the overexpression of a bFGF antisense construct in C6 glioma cells, reduced cell proliferation was observed [24], suggesting that bFGF is essential for the proliferation of tumor cells. Recently, vascular endothelial growth factor (VEGF), its receptor VEGFR, and angiogenic factors were examined in 46 human pituitary adenomas, and the results supported the conclusion that VEGF and its receptor could serve as markers of poor outcome after partial tumor resection [25]. Therefore, gene therapy performed using antisense cDNAs that target bFGF, EGF, VEGF, or their receptors may be an effective approach, and this has been used in treating brain tumorsin animal models[17]. Whereas most of the studies related to suicide gene therapy have used it as an experimental approach in treating pituitary tumors, insulin-like growth factor-I gene therapy was shown to effectively reverse estradiol-induced prolactinomas and somatomammotropic tumors in rats $[26,27]$. ACTH-secreting tumors abundantly express peroxisome proliferator activated receptor (PPAR)- $\gamma$, and pharmacological treatment with PPAR- $\gamma$ activators induced cell cycle arrest and apoptosis in these tumors, suggesting that gene-therapy interventions involving PPAR- $\gamma$ could be beneficial in the treatment of pituitary tumors [28].

\section{Gene therapy in thyroid cancer}

Thyroid cancer is described as a malignant neoplasm of follicular or parafollicular thyroid cells. Most thyroid tumors are benign, and primary malignant tumors account for $<1 \%$ of all carcinomas [29]. According to the SEER Cancer Statistics of the US National Cancer Institute (NCI), 60,220 people (14,910 men and 45,310 women) will be diagnosed with thyroid cancer in 2013 and 1,850 men and women will die because of the cancer (seer.cancer.gov/statfacts/html/thyro. html\#incidence-mortality). Medullary thyroid carcinoma originates from calcitonin-secreting parafollicular cells (C-Cells). Although rare, this carcinoma contributes substantially to the mortality rate. Medullary thyroid cancer is more challenging to treat with conventional chemotherapies or radio-iodine therapy than papillary or follicular thyroid cancer because medullary thyroid cancers respond poorly to these therapies [30]. Despite the progress made in the treatment of thyroid tumors by using various methods such as surgery, chemotherapy, and radiotherapy, the efforts to prevent mortality fall short. Because conventional treatment strategies used for thyroid cancers fail, alternate approaches such as gene therapies are of considerable interest. Notably, the promoters of thyroglobulin (TG), TSH receptor, and calcitonin exhibit no expression or limited expression outside the thyroid gland, and the complete destruction of the thyroid gland by using therapies does not have a major impact when compared with the destruction of other critical tissues such as those of the liver and lungs. These two reasons make thyroid tumors a good target for gene therapy in which the aforementioned promoters are used [31]. Numerous gene-therapy approaches (represented in Fig. 3) have been developed for treating medullary thyroid carcinoma and the following are some of these approaches, as reviewed elsewhere [32].

1. Using dominant-negative RET mutants or ribozymes to inhibit the RET oncogene in medullary thyroid carcinoma (RET encodes a receptor that has tyrosine kinase activity and acts as a protooncogene);

2. Cytoreductive gene therapy performed using prodrug-activating enzymes and the sodium iodide symporter gene (that increases the uptake of I-131);

3. Immunomodulatory gene therapy; and

4. Combined cytoreductive and immunomodulatory gene therapy.

Based on using these approaches, several studies have described the outcomes of the gene-therapy approaches in the treatment of thyroid cancer [32-37].

Cengic et al. reported that I-131 exhibited a thera- 


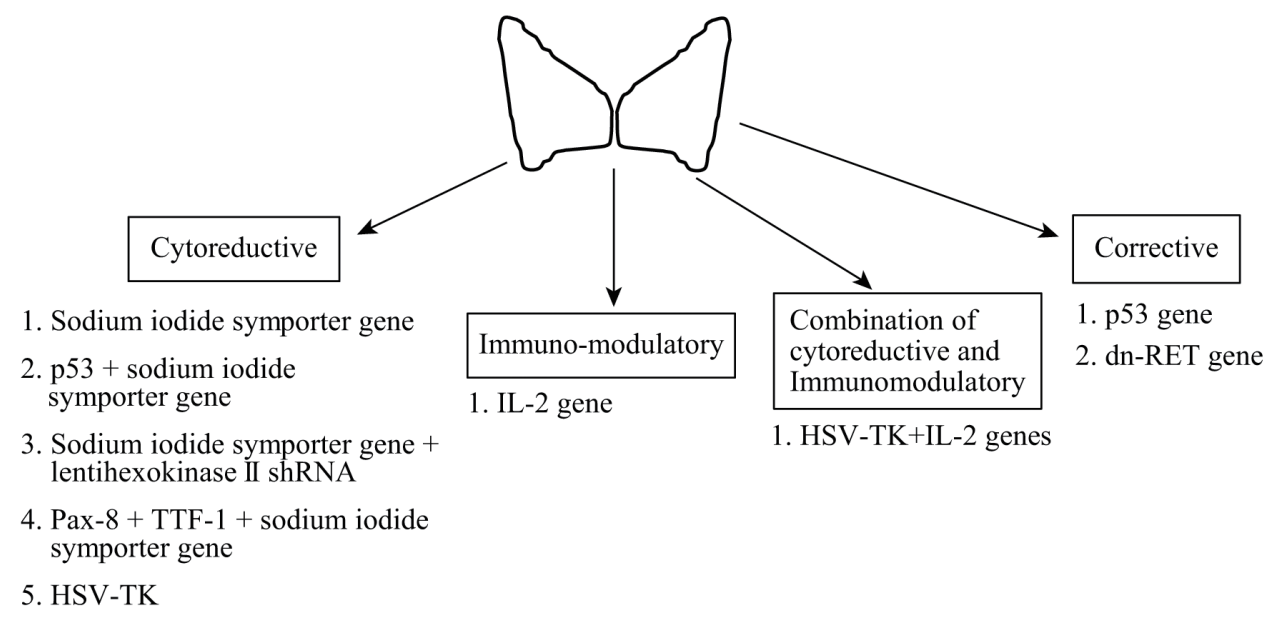

Fig. 3 Gene therapy for thyroid cancer

Different approaches and therapeutic genes under each approach are depicted in this schematic diagram. Readers may refer the text for more details

peutic effect in medullary thyroid cancer cells that had been stably transfected with the sodium iodide symporter gene by using a tissue-specific calcitonin promoter [30]. This calcium-driven sodium iodide symporter induced tumor-specific iodide uptake activity [30]. In another study by Spitzweg et al., the transfer of the sodium iodide symporter gene was performed in vivo in human medullary thyroid cancer cell xenografts by using adenoviral vectors featuring specific promoters, either a cytomegalovirus promoter, or a carcinoembryonic antigen promoter; in this study, following adenovirus-mediated induction of the tumor-specific sodium symporter gene, I-131 was demonstrated to be therapeutically effective [38]. After cotransfecting wildtype p53 and sodium iodide symporter genes in human anaplastic thyroid carcinoma cells, Lee et al. observed an enhanced cytotoxic effect upon treatment with betaemitter radionuclides [39]. Human sodium iodide symporter gene-mediated radioiodine therapy in anaplastic thyroid cancer was demonstrated in vivo, which indicated the feasibility of using this approach in the treatment of anaplastic thyroid cancer [40]. Single-modality gene therapy has limitations, and the antitumor effects against anaplastic thyroid carcinoma obtained by combining I-131 and human sodium iodide symporter gene therapy with lenti-hexokinase II shRNA were stronger in a mouse model than the effects of single-modality gene therapy alone [41]. Using doxorubicin enhances transgene expression under the control of the Cytomegalo virus promoter, which can be useful when performing sodium iodide symporter gene transfer coupled with radioiodine therapy in anaplastic thyroid carcinoma [42]. In vivo tumor imaging and guided radioiodine therapy have been attempted together with gene-therapeutic approaches [38, 43]. Pax-8 and thyroid transcription factor (TTF-1) are transcriptional factors that regulate the expression of thyroid specific proteins involved in the uptake of iodine by the thyroid gland. Recently, the transduction of Pax- 8 alone or in combination with TTF-1 was shown to result in enhanced sodium iodide symporter-mediated radioiodine accumulation in thyroid carcinoma cells, which suggests that this method could serve as a potential gene-therapeutic approach in the treatment of thyroid cancer [44].

In a distinct approach used by Soler et al., ganciclovir effectively eradicated tumors in $60 \%$ of Wag/RiJ rats in which tumors were generated using orthotopic injection of the rMTC 6-23 cell line and/or its derivatives expressing the HSV1-TK gene (rMTC-TK). HSV1-TK transforms ganciclovir into a toxic metabolite, which forms the core principle of the suicide therapy that eradicated the tumors in the animals (represented in Fig. 2) [45]. Subsequently, together with the rMTC-TK cells, cells transfected to express the interleukin (IL)-2 gene (rMTC-IL-2) were inoculated, and the tumors generated by these combined cells showed superior response when treated with both ganciclovir and IL-2 [45]. IL-2 enhances the antitumor activity of $\mathrm{T}$ cells and natural killer cells. A highly efficient multi-gene antitumor treatment was developed in 
which an adenoviral vector expressing both HSV1-TK and human IL-2 (AdCMVTKhIL2) was generated [46]. This AdCMVTKhIL2 vector efficiently produced both HSV1-TK and human IL-2 and exhibited effective antitumor activity [46]. In a pilot study, 2 patients afflicted with end-stage anaplastic thyroid carcinoma were injected with a retroviral vector carrying human IL-2 and the suicide gene HSV1-TK, and tumor necrosis was demonstrated together with few adverse effects [47]. Barzon et al. modified a retroviral vector by replacing the viral enhancer with the enhancer sequence of human $\mathrm{TG}$, and this TG enhancer transcriptionally drove the targeting of both HSV1-TK and IL-2 [48]. When using tumor-specific promoters with HSV1-TK/ganciclovir, cytotoxicity in transcriptionally targeted cancer gene therapy is enhanced by using the Cre-loxP system [33]. Besides the use of viral vectors, direct injection of a plasmid expressing NOS2 cDNA into rat MTC xenograft tumors caused apoptotic cell death; theNOS gene encodes nitric oxide synthase, and nitric oxide has been shown to be cytotoxic to tumor cells [49].

\section{Gene therapy in adrenal tumors}

Adrenocortical tumors are rare but highly malignant, and their incidence is 2 per million people/year [50]. The molecular mechanisms underlying the pathogenesis of adrenocortical tumors are poorly understood, and the treatment options available for the tumors are limited to medical and radiation therapies coupled with surgery. Alternative therapeutic strategies that are more effective than those currently available are required to treat patients with adrenocortical tumors. To express therapeutic genes in adrenal tumors, the CYP11B1 promoter was used in in vitro studies. The steroidogenic gene CYP11B1 (11ß-hydroxylase) was shown to be expressed in normal adrenal tissue and in 32 adrenocortical cancer samples, with minimal expression in ovaries/testes and no expression in any other tumors being detected [51]. Thus, the CYP11B1 promoter can be used specifically to target adrenal tissue. Furthermore, when the expression of the HSV1-TK gene was driven by the CYP11B1 promoter bearing the P450scc enhancer element and this was coupled with ganciclovir in stably transfected Y-1 adrenal cells, ganciclovir sensitivity was enhanced following treatment with 8-bromo-cAMP, forskolin, and ACTH [51]. This appears to be a potential gene-therapy approach that could be applied in in vivo studies. However, several additional studies are required to determine the impact of gene therapy in adrenal tumors.

\section{Gene therapy for ovarian and testicular cancer}

Cancerous growth detected in the ovaries can be ovarian epithelial carcinomas (cells on the surface of the ovary) or malignant germ-cell tumors (tumors in the egg cells). According to the US NCI, the estimated number of new cases of ovarian cancer and the deaths caused by it in USA in 2013 are 22,240 and 14,030 respectively. Current therapies used for ovarian carcinoma are ineffective because of delayed diagnosis, tumor recurrence, resistance to platinum-based chemotherapy, and the side effects of various drugs. Targeting ovarian cancer cells specifically with conventional chemotherapeutic drugs is another major challenge. Given the failure of current therapies, new therapeutic strategies are critically required not only to cure the cancer but also to improve the quality of life and produce few side effects. Gene therapies performed using the intraperitoneal route are well suited in the case of ovarian cancer because the disease remains disseminated in the abdominal cavity [52]. Studies comparing lentiviral and retroviral vectors in mediating gene transfer in ovarian cancer cells indicated that lentiviral vectors were efficient in gene transfer both in vitro and in vivo [53]. Intra-peritoneal administration of a replication-deficient adenovirus encoding human recombinant wild-type p53 and combining this with platinum-based chemotherapy substantially reduced serum CA125 levels in patients with recurrent ovarian cancer [54]. However, randomized Phase II/III trials of p53 gene therapy for use in first-line treatment of patients with ovarian cancer did not show adequate therapeutic effects [55]. This may have been because of various problems such as the dominant-negative crosstalk between ectopic wild-type p53 and the overexpressed p53 mutant in ovarian cancer, heterogeneity, or a lack of Coxsackie-adenovirus receptors and integrin coreceptors in ovarian tumors and the presence of neutralizing antibodies in ovarian cancer-related ascites [55]. In a study conducted by Hung et al., intra-peritoneal injection of HPV-16 pseudovirions carrying the HSV1-TK gene followed by the administration of ganciclovir showed marked antitumor effects in ovarian cancer-bearing mice [56]. Papillomavirus pseudovirions are DNA plasmids packed into the papillomavi- 
rus L1 and L2 capsid proteins that are stable, and the encapsulation protects the DNA against nuclease action [56]. Moreover, because several types of pseudovirions are available, switching to other pseudovirion types is possible when neutralizing antibodies are present [56]. MUC1, a tumor-associated antigen involved in cellular transformation and tumorigenicity, is overexpressed in $>90 \%$ of late-stage epithelial ovarian cancers, and hence combinatorial use of anti-MUC1 antibody and docetaxel effectively reduced tumors in a mouse model of ovarian cancer [57]. Intra-peritoneal administration of engineered mesothelial cells expressing HSV1-TK substantially increased the survival of animals with ovarian cancer [58]. This method again exploited the principle of suicide gene therapy to treat ovarian cancer. Virotherapy strategies used for ovarian cancer have certain limitations, and this led to the construction of two novel conditionally replicative adenoviruses [59]. These approaches resulted in enhanced specificity coupled with high infectivity/replication rate in ovarian cancer cells [59]. Resistance to chemotherapy is another problem that is observed in numerous cancer types. In this regard, Lu et al. demonstrated a specific killing effect of 5-flurocytosine on taxol-resistant ovarian cancer cells by using adenovirus-mediated transfer of cytosine deaminase and uracil phosphoribosyl transferase genes, which were directed by the multidrug resistance gene 1 promoter [60].

Testicular cancer is the cancer of the testicles. According to American Cancer Society, 7,920 new cases of testicular cancer will occur in USA in 2013, and 370 of those affected will die because of the cancer. Although the prevalence rate is lower than that of ovarian cancer, the rate of testicular cancer has been increasing in USA and worldwide. Patients with testicular cancer are typically treated with chemotherapy coupled with or without surgery. Alternative therapeutic strategies must be developed for testicular cancer, especially for those patients in whom relapse occurs following conventional treatment. When tissue-specific hCG-beta promoters were used, treatment with a recombinant adenovirus carrying the TK gene together with acyclovir potently inhibited tumor/cancer-cell growth both in vitro and in vivo [61]. REIC/Dkk-3, a member of the human dickkopf (Dkk) family, has been reported to suppress cancer growth, and the overexpression of this protein by using an adenovirus vector (Ad-REIC) induced apoptosis in the testicular germcell cancer cell line NCCIT (and also inhibited tumor growth in nude mice) [62]. This result raises the possibility of using therapeutic measures involving genetherapy approaches against human testicular cancer.

\section{Gene therapy in neuroendocrine tumors}

Neuroendocrine tumors are highly heterogeneous neoplasms that arise from the dispersed neuroendocrine system (cells of both endocrine and nervous systems). Gastroenteropancreatic (GEP) neuroendocrine tumors (NET) encompass neoplasms that secrete peptides and neuroamines that cause distinct clinical syndromes including carcinoid syndrome [63]. Pancreatic endocrine tumors are extremely rare, with an annual incidence less than 1 per 100,000 [64]. Strategies used to manage these tumors include surgery, radiological intervention, chemotherapy, and treatment with somatostatin analogs [63]. Pancreatic NETs can be functional (insulinomas, glucagonomas, somatostatinomas, gastrinomas, VIPomas (VIP: vasoactive intestinal peptide), GRFomas, and ACTHomas) or nonfunctional (tumors that do not produce any hormones). Midgut carcinoids arise from enterochromaffin cells in the mucosa of jejunum, ileum, cecum, and the ascending colon [65]. These cells produce various peptides and hormones [65]. Midgut carcinoids metastasize to the mesentery and the liver, and because efficient therapeutic options are unavailable, successful new therapies must be established. Chromogranin A, an acidic hydrophilic protein expressed in the endocrine and neuronal cells of the neuroendocrine tissues [66], is highly expressed in various tumors such as carcinoid, neuroblastoma, pheochromocytoma, and medullary thyroid tumors, pancreatic islet-cell tumors, small-cell lung carcinomas, and prostate cancer [67]. Leja et al. engineered a novel oncolytic adenovirus in which the chromogranin-A promoter controlled the expression of the adenoviral E1A gene. This novel oncolytic adenovirus specifically suppressed carcinoid tumors induced by the human pancreatic-tumor cell line BON in nude mice, suggesting that this treatment could potentially be used in therapies in conjunction with standard therapies [67]. When the oncolytic adenovirus was further modified where $\mathrm{CgA}$ promoter controls E1A with miR122 target sequences in 3'UTR, there is reduced E1A protein expression and arrest of viral replication in miR122 expressing hepatic cells; this prevented toxicity in the normal hepatocytes in carcinoid tumor metastasis and enabled the use of high doses of the 
oncolytic virus in treating the tumors [68]. In another approach, an infection-enhanced and replication-selective oncolytic adenovirus that was engineered to express Helicobacter pylori neutrophil-activating protein (HP-NAP) showed favorable results in the treatment of solid tumors [69]. HP-NAP can produce antitumor effects by recruiting neutrophils (by overcoming the immunosuppressive tumor environment) and may thus serve as a therapeutic gene [69]. Treatment with this oncolytic virus enhanced the survival of nude mice bearing BON neuroendocrine tumors [69]. Mice implanted with human interferon- $\alpha 2$-expressing BON cells showed a lower incidence and delayed development of tumors compared with wild-type mice, indicating the potential for using this treatment for neuroendocrine tumors [70].

\section{Gene therapy clinical trials}

Among all clinical trials, $>65 \%$ of the gene therapy trials conducted have been devoted to cancers [71]. Various vectors and methods have been employed in gene therapy clinical trials: retroviruses $(20 \%)$; adenoviruses (18\%); adeno-associated viruses (5\%); lipofection (6\%); and naked/plasmid DNA (18.5\%) [71]. Among 1,186 cancer gene therapy trials (out of 1,843), only 45 have reached Phase III and one is in Phase IV [71]. Only 9 gene therapy clinical trials have been conditionally approved so far based on the outcome [71]. According to the US NCI, a Phase IV r-Ad-p53 gene therapy developed for advanced malignant thyroid tumors is active, and the primary objective of this study is to determine the efficacy of intra-tumor injection of rAd-p53 when coupled with radioactive iodine or combined with surgery in advanced thyroid tumors (www. cancer.gov). Preclinical studies employing gene-therapy strategies are encouraging in the case of certain endocrine tumors, and gene therapy is expected to successfully treat these tumors.

\section{Conclusions and perspectives}

The gene-therapy approaches used in treating various endocrine tumors mentioned in this review (summarized in Table 1) illustrate the future possibilities and applications of gene therapy. To increase the success and efficiency of antitumor gene-therapy strategies, the molecular pathways involved in endocrine tumorigenicity must be understood. We expect gene therapy to improve treatment quality and clinical outcomes in various endocrine tumors. However, progress in using gene therapy is unlikely unless the efforts

Table 1 Summary of gene therapeutic approaches in endocrine tumors

\begin{tabular}{|c|c|c|c|c|c|c|}
\hline & Pituitary tumors & Thyroid tumors & $\begin{array}{l}\text { Adrenal } \\
\text { tumors }\end{array}$ & $\begin{array}{l}\text { Ovarian } \\
\text { tumors }\end{array}$ & $\begin{array}{l}\text { Testicular } \\
\text { tumors }\end{array}$ & $\begin{array}{c}\text { Neuroendocrine } \\
\text { tumors }\end{array}$ \\
\hline Vector systems & $\begin{array}{l}\text { Adeno virus, } \\
\text { AAV, retrovirus, } \\
\text { lentivirus, HSV } \\
\text { and non-viral } \\
\text { approaches }\end{array}$ & $\begin{array}{l}\text { Adenovirus, } \\
\text { lentivirus and } \\
\text { retrovirus }\end{array}$ & Adenovirus & Lentivirus, retrovirus & Adenovirus & Adenovirus \\
\hline $\begin{array}{l}\text { Therapeutic } \\
\text { genes }\end{array}$ & $\begin{array}{l}\text { HSV-TK, } \\
\text { tyrosine } \\
\text { hydroxylase, } \\
\text { TNF- } \alpha \text {, FasL, } \\
\text { bFGF antisense } \\
\text { construct, IGF-1 }\end{array}$ & $\begin{array}{l}\text { Sodium iodide } \\
\text { symporter, p53, } \\
\text { Pax-8, TTF-1, } \\
\text { HSV-TK, IL-2, } \\
\text { NOS2 }\end{array}$ & HSV-TK & $\begin{array}{l}\text { p53, HSV-TK, } \\
\text { cytosine deaminase and } \\
\text { uracil phosphori bosyl } \\
\text { transferase genes }\end{array}$ & REIC/Dkk-3 & Adenoviral E1A \\
\hline $\begin{array}{l}\text { Targetting } \\
\text { strategies }\end{array}$ & $\begin{array}{l}\text { Using cell } \\
\text { specific } \\
\text { promoters GH, } \\
\text { PRL, ACTH, } \\
\text { POMC, } \\
\text { Phosphoglycerate } \\
\text { kinase etc. } \\
\text { Cre-lox P }\end{array}$ & $\begin{array}{l}\text { Using cell specific } \\
\text { promoter Calcitonin, } \\
\text { Carcinoembryonic } \\
\text { antigen promoter, } \\
\text { cytomegalovirus } \\
\text { promoter } \\
\text { Cre-lox-P, } \\
\text { Cytoreductive } \\
\text { alone and in } \\
\text { combination with } \\
\text { immunomodulatory } \\
\text { gene therapy }\end{array}$ & $\begin{array}{l}\text { Using cell } \\
\text { specific } \\
\text { promoter } \\
\text { CYP11B1 }\end{array}$ & Using MDR1 promoter & $\begin{array}{l}\text { hCG-beta } \\
\text { promoter }\end{array}$ & $\begin{array}{l}\text { Chromogranin- } \\
\text { A promoter }\end{array}$ \\
\hline
\end{tabular}


of basic scientists and clinicians are integrated to tackle the clinical challenges posed by gene therapy and make it successful.

\section{Acknowledgements}

We would like to thank the management of VIT for providing help and support. We apologize to the many scientists whose work was not credited because of space limitations; in some cases, reviews have been cited at the expense of original work. This work was supported by the Japan Society for the Promotion of Sciences, Tokyo JSPS KAKENHI 24650489 (R.T).

No conflict of interest exists.

\section{References}

1. Barzon L, Boscaro M, Palu G (2004) Endocrine aspects of cancer gene therapy. Endocr Rev 25: 1-44.

2. Ginn SL, Alexander IE, Edelstein ML, Abedi MR, Wixon J (2013) Gene therapy clinical trials worldwide to 2012 - an update. J Gene Med 15: 65-77.

3. Ezzat S, Asa SL, Couldwell WT, Barr CE, Dodge WE, et al. (2004) The prevalence of pituitary adenomas: a systematic review. Cancer 101: 613-619.

4. Nilsson B, Gustavsson-Kadaka E, Bengtsson BA, Jonsson B (2000) Pituitary adenomas in Sweden between 1958 and 1991: incidence, survival, and mortality. J Clin Endocrinol Metab 85: 1420-1425.

5. Davis JR, Farrell WE, Clayton RN (2001) Pituitary tumours. Reproduction 121: 363-371.

6. Kaltsas GA, Nomikos P, Kontogeorgos G, Buchfelder M, Grossman AB (2005) Diagnosis and management of pituitary carcinomas. J Clin Endocrinol Metab 90: 3089-3099.

7. Swensen R, Kirsch W (2002) Brain neoplasms in women: a review. Clin Obstet Gynecol 45: 904-927.

8. Seilicovich A, Pisera D, Sciascia SA, Candolfi M, Puntel M, et al. (2005) Gene therapy for pituitary tumors. Curr Gene Ther 5: 559-572.

9. Lee EJ, Jameson JL (2005) Gene therapy of pituitary diseases. J Endocrinol 185: 353-362.

10. Sudhakar N, Ray A, Vafidis JA (2004) Complications after trans-sphenoidal surgery: our experience and a review of the literature. Br J Neurosurg 18: 507-512.

11. Schlechte JA (2007) Long-term management of prolactinomas. J Clin Endocrinol Metab 92: 2861-2865.

12. Melmed S, Casanueva FF, Cavagnini F, Chanson P, Frohman L, et al. (2002) Guidelines for acromegaly management. J Clin Endocrinol Metab 87: 4054-4058.

13. Beck-Peccoz P, Persani L (2002) Medical management of thyrotropin-secreting pituitary adenomas. Pituitary 5: 83-88.

14. Barzon L, Bonaguro R, Palù G, Boscaro M (2000) New perspectives for gene therapy in endocrinology. Eur $J$ Endocrinol 143: 447-466.

15. Goya RG, Rowe J, Sosa YE, Tomasec P, Lowenstein PR, Castro MG (1998) Use of recombinant herpes simplex virus type 1 vectors for gene transfer into tumour and normal anterior pituitary cells. Mol Cell Endocrinol
139: 199-207.

16. Tomasec P, Preston CM, Linton EA, Ahmed I, Lowenstein PR, Castro MG (1999) Generation of a recombinant herpes simplex virus type 1 expressing the rat corticotropin-releasing hormone precursor: endoproteolytic processing, intracellular targeting and biological activity. Neuroendocrinology 70: 439-450.

17. Castro MG, Cowen R, Williamson IK, David A, Jimenez-Dalmaroni MJ, et al. (2003) Current and future strategies for the treatment of malignant brain tumors. Pharmacol Ther 98: 71-108.

18. Walls GV, Lemos MC, Javid M, Bazan-Peregrino M, Jeyabalan J, et al. (2012) MEN1 gene replacement therapy reduces proliferation rates in a mouse model of pituitary adenomas. Cancer Res 72: 5060-5068.

19. Lee EJ, Martinson F, Kotlar T, Thimmapaya B, Jameson JL (2001) Adenovirus-mediated targeted expression of toxic genes to adrenocorticotropin-producing pituitary tumors using the proopiomelanocortin promoter. J Clin Endocrinol Metab 86: 3400-3409.

20. Windeatt S, Southgate TD, Dewey RA, Bolognani F, Perone MJ, et al. (2000) Adenovirus-mediated herpes simplex virus type-1 thymidine kinase gene therapy suppresses oestrogen-induced pituitary prolactinomas. J Clin Endocrinol Metab 85: 1296-1305.

21. Williams JC, Stone D, Smith-Arica JR, Morris ID, Lowenstein PR, Castro MG (2001) Regulated, adenovirus-mediated delivery of tyrosine hydroxylase suppresses growth of estrogen-induced pituitary prolactinomas. Mol Ther 4: 593-602.

22. Roche C, Zamora AJ, Taïeb D, Lavaque E, Rasolonjanahary R, et al. (2004) Lentiviral vectors efficiently transduce human gonadotroph and somatotroph adenomas in vitro. Targeted expression of transgene by pituitary hormone promoters. J Endocrinol 183: 217233.

23. Candolfi M, Jaita G, Pisera D, Ferrari L, Barcia C, et al. (2006) Adenoviral vectors encoding tumor necrosis factor-alpha and FasL induce apoptosis of normal and tumoral anterior pituitary cells. J Endocrinol 189: 681690.

24. Redekop GJ, Naus CC (1995) Transfection with bFGF sense and antisense cDNA resulting in modification of 
malignant glioma growth. J Neurosurg 82: 83-90.

25. Sanchez-Ortiga R, Sanchez-Tejada L, Moreno-Perez O, Riesgo P, Niveiro M, Picó Alfonso AM (2013) Overexpression of vascular endothelial growth factor in pituitary adenomas is associated with extrasellar growth and recurrence. Pituitary 16: 370-377.

26. Console GM, Herenu CB, Camihort GA, Luna GC, Bracamonte MI, et al. (2008) Insulin-like growth factor-I gene therapy reverses morphologic changes and reduces hyperprolactinemia in experimental rat prolactinomas. Mol Cancer 7: 13.

27. Cónsole GM, Hereñú CB, Camihort GA, Luna GC, Ferese C, Goya RG (2009) Effect of insulin-like growth factor-I gene therapy on the somatotropic axis in experimental prolactinomas. Cell Tissues Organs 190: 20-26.

28. Heaney AP, Fernando M, Yong WH, Melmed S (2002) Functional PPAR-gamma receptor is a novel therapeutic target for ACTH-secreting pituitary adenomas. Nat Med 8: 1281-1287.

29. Al-Humadi H, Zarros A, Al-Saigh R, Liapi C (2010) Genetic basis and gene therapy trials for thyroid cancer. Cancer Genomics Proteomics 7: 31-49.

30. Cengic N, Baker CH, Schütz M, Göke B, Morris JC, Spitzweg C (2005) A novel therapeutic strategy for medullary thyroid cancer based on radioiodine therapy following tissue-specific sodium iodide symporter gene expression. J Clin Endocrinol Metab 90: 4457-4464.

31. DeGroot LJ, Zhang R (2001) Clinical review 131: Gene therapy for thyroid cancer: where do we stand. J Clin Endocrinol Metab 86: 2923-2928.

32. Messina M, Robinson BG (2007) Technology insight: gene therapy and its potential role in the treatment of medullary thyroid carcinoma. Nat Clin Pract Endocrinol Metab 3: 290-301.

33. Nagayama $Y$, Nishihara E, Iitaka $M$, Namba $H$, Yamashita S, Niwa M (1999) Enhanced efficacy of transcriptionally targeted suicide gene/prodrug therapy for thyroid carcinoma with the Cre-loxP system. Cancer Res 59: 3049-3052.

34. Braiden V, Nagayama Y, Iitaka M, Namba H, Niwa M, Yamashita S (1998) Retrovirus-mediated suicide gene/ prodrug therapy targeting thyroid carcinoma using a thyroid-specific promoter. Endocrinology 139: 39963999.

35. Lausson S, Fournes B, Borrel C, Milhaud G, TreilhouLahille F (1996) Immune response against medullary thyroid carcinoma (MTC) induced by parental and/ or interleukin-2-secreting MTC cells in a rat model of human familial medullary thyroid carcinoma. Cancer Immunol Immunother 43: 116-123.

36. Yamazaki M, Zhang R, Straus FH, Messina M, Robinson BG, et al. (2002) Effective gene therapy for medullary thyroid carcinoma using recombinant adenovirus inducing tumor-specific expression of interleukin-12. Gene Ther 9: 64-74.
37. Yamazaki M, Straus FH, Messina M, Robinson BG, Takeda T, et al. (2004) Adenovirus-mediated tumor-specific combined gene therapy using Herpes simplex virus thymidine/ganciclovir system and murine interleukin-12 induces effective antitumor activity against medullary thyroid carcinoma. Cancer Gene Ther 11: 8-15.

38. Spitzweg C, Baker CH, Bergert ER, O'Connor MK, Morris JC (2007) Image-guided radioiodide therapy of medullary thyroid cancer after carcinoembryonic antigen promoter-targeted sodium iodide symporter gene expression. Human gene therapy 18: 916-924.

39. Lee YJ, Chung JK, Kang JH, Jeong JM, Lee DS, Lee MC (2010) Wild-type p53 enhances the cytotoxic effect of radionuclide gene therapy using sodium iodide symporter in a murine anaplastic thyroid cancer model. Eur J Nucl Med Mol Imaging 37: 235-241.

40. Hsieh YJ, Ke CC, Liu RS, Wang FH, Tang KT, et al. (2007) Radioiodide imaging and treatment of ARO cancer xenograft in a mouse model after expression of human sodium iodide symporter. Anticancer Res 27: 2515-2522.

41. Kim JE, Ahn BC, Hwang MH, Jeon YH, Jeong SY, et al. (2011) Combined RNA interference of hexokinase II and (131)I-sodium iodide symporter gene therapy for anaplastic thyroid carcinoma. J Nucl Med 52: 17561763.

42. Kim KI, Kang JH, Chung JK, Lee YJ, Jeong JM, et al. (2007) Doxorubicin enhances the expression of transgene under control of the CMV promoter in anaplastic thyroid carcinoma cells. J Nucl Med 48: 1553-1561.

43. Ke CC, Hsieh YJ, Hwu L, Wang FH, Chen FD, et al. (2011) Evaluation of lentiviral-mediated expression of sodium iodide symporter in anaplastic thyroid cancer and the efficacy of in vivo imaging and therapy. J Oncol 2011: 178967

44. Mu D, Huang R, Li S, Ma X, Lou C, Kuang A (2012) Combining transfer of TTF-1 and Pax- 8 gene: a potential strategy to promote radioiodine therapy of thyroid carcinoma. Cancer Gene Ther 19: 402-411.

45. Soler MN, Milhaud G, Lekmine F, Treilhou-Lahille F, Klatzmann D, Lausson S (1999) Treatment of medullary thyroid carcinoma by combined expression of suicide and interleukin-2 genes. Cancer Immunol Immunother 48: 91-99.

46. Zhang R, DeGroot LJ (2001) An adenoviral vector expressing functional heterogeneous proteins herpes simplex viral thymidine kinase and human interleukin-2 has enhanced in vivo antitumor activity against medullary thyroid carcinoma. Endocr Relat Cancer 8: 315325.

47. Barzon L, Pacenti M, Taccaliti A, Franchin E, Bruglia M, et al. (2005) A pilot study of combined suicide/ cytokine gene therapy in two patients with end-stage anaplastic thyroid carcinoma. J Clin Endocrinol Metab 90: 2831-2834. 
48. Barzon L, Bonaguro R, Castagliuolo I, Chilosi M, Gnatta E, et al. (2002) Transcriptionally targeted retroviral vector for combined suicide and immunomodulating gene therapy of thyroid cancer. J Clin Endocrinol Metab 87: 5304-5311.

49. Soler MN.Bobé P, Benihoud K, Lemaire G, Roos BA, Lausson S (2000) Gene therapy of rat medullary thyroid cancer by naked nitric oxide synthase II DNA injection. J Gene Med 2: 344-352.

50. Schteingart DE, Doherty GM, Gauger PG, Giordano TJ, Hammer GD, et al. (2005) Management of patients with adrenal cancer: recommendations of an international consensus conference. Endocr Relat Cancer 12: 667680 .

51. Chuman Y, Zhan Z, Fojo T (2000) Construction of gene therapy vectors targeting adrenocortical cells: enhancement of activity and specificity with agents modulating the cyclic adenosine 3',5'-monophosphate pathway. $J$ Clin Endocrinol Metab 85: 253-262.

52. Matthews KS, Alvarez RD, Curiel DT (2009) Advancements in adenoviral based virotherapy for ovarian cancer. Adv Drug Deliv Rev 61: 836-841.

53. Indraccolo S, Habeler W, Tisato V, Stievano L, Piovan $\mathrm{E}$, et al. (2002) Gene transfer in ovarian cancer cells: a comparison between retroviral and lentiviral vectors. Cancer Res 62: 6099-6107.

54. Buller RE, Runnebaum IB, Karlan BY, Horowitz JA, Shahin M, et al. (2002) A phase I/II trial of $\mathrm{rAd} / \mathrm{p} 53$ (SCH 58500) gene replacement in recurrent ovarian cancer. Cancer Gene Ther 9: 553-566.

55. Zeimet AG, Marth C (2003) Why did p53 gene therapy fail in ovarian cancer. Lancet Oncol 4: 415-422.

56. Hung CF, Chiang AJ, Tsai HH, Pomper MG, Kang TH, et al. (2012) Ovarian cancer gene therapy using HPV-16 pseudovirion carrying the HSV-tk gene. PLoS One 7(7): e40983

57. Wang L, Chen H, Pourgholami MH, Beretov J, Hao J, et al. (2011) Anti-MUC1 monoclonal antibody (C595) and docetaxel markedly reduce tumor burden and ascites, and prolong survival in an in vivo ovarian cancer model. PLoS One 6: e24405.

58. Rancourt C, Bergeron C, Lane D, Garon G, Piché A (2003) Delivery of herpes simplex thymidine kinase bystander effect by engineered human mesothelial cells for the treatment of ovarian cancer. Cytotherapy 5: 509522.

59. Rocconi RP, Zhu ZB, Stoff-Khalili M, Rivera AA, Lu
B, et al. (2007) Treatment of ovarian cancer with a novel dual targeted conditionally replicative adenovirus (CRAd). Gynecol Oncol 105: 113-121.

60. Lu S, Wang X, Xiao L, Cai L, Zhang Y, et al. (2007) Gene therapy for ovarian cancer using adenovirusmediated transfer of cytosine deaminase gene and uracil phosphoribosyl transferase gene directed by MDR1 promoter. Cancer Biol Ther 6: 397-404.

61. Shirakawa T, Gotoh A, Zhang Z, Kao C, Chung LW, Gardner TA (2004) Development of human chorionic gonadotropin subunit-beta promoter-based toxic gene therapy for testicular cancer. Urology 63: 613-618.

62. Tanimoto R, Abarzua F, Sakaguchi M, Takaishi M, Nasu Y, et al. (2007) REIC/Dkk-3 as a potential gene therapeutic agent against human testicular cancer. Int $J$ Mol Med 19: 363-368.

63. Modlin IM, Oberg K, Chung DC, Jensen RT, de Herder WW, et al. (2008) Gastroenteropancreatic neuroendocrine tumours. Lancet Oncol 9: 61-72.

64. Halfdanarson TR, Rubin J, Farnell MB, Grant CS, Petersen GM (2008) Pancreatic endocrine neoplasms: epidemiology and prognosis of pancreatic endocrine tumors. Endocr Relat Cancer 15: 409-427.

65. Oberg KE (2010) Gastrointestinal neuroendocrine tumors. Ann Oncol 21 Suppl 7: vii72-80.

66. Simon JP, Aunis D (1989) Biochemistry of the chromogranin A protein family. Biochem J 262: 1-13.

67. Leja J, Dzojic H, Gustafson E, Oberg K, Giandomenico V, Essand M (2007) A novel chromogranin-A promoterdriven oncolytic adenovirus for midgut carcinoid therapy. Clin Cancer Res 13: 2455-2462.

68. Leja J, Nilsson B, Yu D, Gustafson E, Akerström G, et al. (2010) Double-detargeted oncolytic adenovirus shows replication arrest in liver cells and retains neuroendocrine cell killing ability. PLoS One 5: e8916.

69. Ramachandran M, Yu D, Wanders A, Essand M, Eriksson F (2013) An Infection-enhanced Oncolytic Adenovirus Secreting H. pylori Neutrophil-activating Protein with Therapeutic Effects on Neuroendocrine Tumors. Mol Ther 21: 2008-2018.

70. Liu M, Kilarski WW, Gerwins P, Oberg K, Zhou Y (2005) Efficient human interferon-alpha gene transfer to neuroendocrine tumor cells with long-term and stable expression. Neuroendocrinology 82: 264-273.

71. Barar J, Omidi Y (2012) Translational Approaches towards Cancer Gene Therapy: Hurdles and Hopes. Bioimpacts 2: 127-143. 